\title{
Feasibility of structured endurance training and Mediterranean diet in BRCA1 and $B R C A 2$ mutation carriers - an interventional randomized controlled multicenter trial (LIBRE-1)
}

Marion Kiechle ${ }^{1 *}$, Ricarda Dukatz ${ }^{1}$, Maryam Yahiaoui-Doktor ${ }^{2}$, Anika Berling $^{3}$, Maryam Basrai ${ }^{4}$, Vera Staiger ${ }^{4}$, Uwe Niederberger ${ }^{5}$, Nicole Marter ${ }^{5}$, Jacqueline Lammert ${ }^{1}$, Sabine Grill ${ }^{1}$, Katharina Pfeifer ${ }^{1}$, Kerstin Rhiem ${ }^{6}$, Rita K. Schmutzler ${ }^{6}$, Matthias Laudes ${ }^{7}$, Michael Siniatchkin ${ }^{5}$, Martin Halle ${ }^{3,8}$, Stephan C. Bischoff ${ }^{5}$ and Christoph Enge ${ }^{2}$

\begin{abstract}
Background: Women with pathogenic BRCA germline mutations have an increased risk for breast and ovarian cancer that seems to be modified by life-style factors. Though, randomized trials investigating the impact of lifestyle interventions on cancer prevention and prognosis in BRCA carriers are still missing.

Methods: We implemented a multicenter, prospective randomized controlled trial in BRCA1/2 patients, comparing a lifestyle intervention group (IG) with a control group (CG) with the primary aim to prove feasibility. Intervention comprised a structured, individualized endurance training alongside nutrition education based on the Mediterranean diet (MD) for 3 months, plus monthly group training and regular telephone contact during the subsequent 9 months. The CG attended one session on healthy nutrition and the benefits of physical activity. Primary endpoints were feasibility, acceptance and satisfaction over 12 months. Furthermore, effects on physical fitness, diet profile, body mass index (BMI), quality of life and perceived stress were investigated.
\end{abstract}

Results: Sixty-eight participants (mean age 41, mean BMI $23.2 \mathrm{~kg} / \mathrm{m}^{2}$ ) were enrolled, of whom 55 (81\%, $26 \mathrm{IG}$, 29 CG) completed 12 months. 73\% ( $n=26)$ participated in at least $70 \%$ of all intervention sessions. Predictors for drop-outs (19\%; $n=13)$ or non-adherence $(27 \% ; n=7)$ were not found. $73 \%$ rated the program highly and $80 \%$ would participate again. Severe adverse events did not occur. Positive effects in the IG compared to the CG were observed for secondary endpoints: BMI, MD eating pattern and stress levels.

Conclusions: This lifestyle intervention was feasible, safe and well accepted. Positive results on eating habits, physical fitness and stress levels warrant a larger randomized trial.

Trial registration: The study has been retrospectively registered at ClinicalTrials.gov (reference: NCT02087592) on March 12, 2014. The first patient was included on February 24, 2014.

Keywords: BRCA1, BRCA2, Hereditary breast cancer, Hereditary ovarian cancer, Exercise, Mediterranean diet, Psychological support

\footnotetext{
* Correspondence: Marion.Kiechle@tum.de

1Department of Gynecology and Center for Hereditary Breast and Ovarian

Cancer, Klinikum rechts der Isar, Technical University Munich (TUM),

Ismaninger Str. 22, 81675 Munich, Germany

Full list of author information is available at the end of the article
} 


\section{Background}

Women with BRCA germline mutations have considerably increased lifetime risks for breast (55-60\%) and ovarian (16-59\%) cancer $[1,2]$. However, current literature implies that the risk of developing cancer in gene carriers may be influenced through genetic factors (polymorphisms), as well as exogenous factors such as reproductive factors, lifestyle and physical activity during adolescence [3, 4]. The cancer risk is higher, if genotype carriers were obese, physically inactive during their youth, born after 1940 or had no children [5, 6]. Regular physical activity has a tremendous impact on breast cancer incidence, and mortality. The breast cancer risk of pre and postmenopausal women can be reduced by regular training on average by $25 \%$ [7]. Moreover, the engagement in regular physical training reduces the risks of recurrence and mortality in women with breast cancer by $50 \%$ [8] and leads to further advantages like gain in quality of life, increased fitness and improved tolerance of chemotherapy [9].

Hypercaloric nutrition leading to weight gain and obesity also increases the risk of breast cancer in both pre and postmenopausal women $[10,11]$. Obese women with a $\mathrm{BMI}>30 \mathrm{~kg} / \mathrm{m}^{2}$ diseased with breast cancer have a greater risk of developing distant metastases and early mortality [12]. In a prospective study with sporadic breast cancer in patients under adjuvant standard therapy nutritional intervention with calorie and fat-restriction led to a significant reduction in recurrence rates [13]. Furthermore, a first randomized dietary intervention trial postulates a beneficial effect of the Mediterranean dietary (MD) pattern on breast cancer incidence [14]. This diet comprises a high intake of fruit and vegetables, whole grains, legumes, fish and olive oil, and low intakes of red meat and processed foods.

Furthermore, mental stress and depression play a significant role. Although not proven to play a significant role in primary prevention of breast cancer, an optimistic outlook on life and psychological well-being, health, and stress reduction have a positive effect in diseased breast cancer patients, accelerating recovery and even impairing mortality [15-17].

Although retrospective observations lead to the hypothesis that risk-modulating factors may also exist in $B R C A$ associated cancers $[5,6]$, so far randomized trials investigating the impact of lifestyle interventions in prevention of cancer as well as on prognosis in BRCA carriers are missing.

Therefore, we aim to perform a prospective randomized intervention trial assessing, whether a long-term multifactorial lifestyle intervention program, including a structured physical endurance training and nutrition education stressing the MD pattern can lead to a reduction in breast cancer incidence and mortality in BRCA1 and BRCA2 mutation carriers [18]. Before initiation of this large trial, we have performed a pilot trial assessing feasibility and adherence in a smaller group which results we present here.

\section{Methods \\ Study design}

'LIBRE-1' (Lifestyle Intervention study in women with hereditary Breast and ovarian cancer, 1 = pilot) [19] is a multicenter, prospective, two-armed randomized (1:1) controlled clinical trial including women with germline mutations in $B R C A 1$ or $B R C A 2$. The primary aim of this study was to evaluate adherence to and acceptance of a structured, 1-year exercise program combined with a Mediterranean dietary pattern. A detailed description of the study design has been published [19]. The study has been registered at ClinicalTrials.gov (reference: NCT02087592). The ethics committee of all three participating university hospitals approved the study. The ethics review board of the faculty of medicine of the Technical University of Munich has approved the study protocol (Reference $5686 / 13$ ) as well as the ethics committee of the faculty of Medicine of the University Cologne and Kiel (Reference 13-053 and Reference B 235/13).

Briefly, with written consent women aged 18-69 years with pathogenic germline mutations in BRCA1 and $B R C A 2$ were recruited from three university hospitals in Germany (Cologne, Kiel and Munich), which are members of the German Consortium for Hereditary Breast and Ovarian Cancer (GC-HBOC), a national registry for $B R C A 1 / 2$ carriers. Exclusion criteria were medical problems not allowing exercise, e.g. metastatic tumor disease, cardiovascular and lung diseases or severe orthopedic problems; food allergies not allowing consumption of a Mediterranean diet; women who regularly exercise, pregnancy; BMI $<18 \mathrm{~kg} / \mathrm{m}^{2}$ [19].

Sample size for this feasibility trial was determined pragmatically, using the recommended minimum of 30 participants per arm. The group allocation was done using a randomly permuted block randomization with an allocation ratio of 1:1. Randomization was stratified by center and previous diagnosis of cancer. While the CG received an introductory lecture on the positive effects of physical activity on the incidence and prognosis of breast cancer as well as a group lesson on healthy eating based on the recommendations of the German Nutrition Society (DGE), the IG received a structured lifestyle intervention program of increasing physical activity and over 12 months (3 months intensive phase followed by 9 months less intense supervision) [19]. Psychological support was not given, but was monitored by questionnaires (SSCS, EORTC QLQ-C30/-BR23, details see below) as were nutrition habits and level of 
physical activity. All parameters were assessed at baseline (SE/V0), after 3 (V1) and 12 months (V2). Data collection and measurements were performed in each study center and collected in a central electronic database (OpenClinica, Waltham, MA, USA) [19].

Outcomes to assess feasibility and acceptability of key trial parameters were participants' completion of the study program and adherence to the intervention procedures. The primary endpoint of the study was the number of randomized women who successfully completed the first 3 months of the intervention program and remained a participant after 1 year. The study was considered feasible, if at least $70 \%$ of the participants completed 1 year of intervention. Additionally, recruitment and retention rates, safety and adverse events were assessed.

Secondary endpoints of the study included the measurements of quality of life (EORTC QLQ-C30-/BR23) [20, 21], perceived chronic stress (SSCS) [22], Body Mass Index (BMI), eating habits, nutrient and fat calorie intake (EPIC-FFQ) [23-25], adherence to the MD (MEDAS) [26], maximal oxygen intake $\left(\mathrm{VO}_{2}\right.$ peak), ventilatory threshold $\left(\mathrm{O}_{2}\right.$ at VT1) and physical activity (IPAQ) [27, 28].

\section{Statistical analysis}

As this was a feasibility study, all statistical analyses were carried out with an exploratory and descriptive intention only. Thus, we deliberately did not adjust for multiple testing in this setting. All $p$-values are two-sided, and $p$ values $<0.05$ were considered significant with hypothesis generating interpretation. Continuous variables were compared using non-parametric tests for independent (Kruskal-Wallis-Test, Mann-Whitney-U-Test) or paired groups (Friedman-Test, Wilcoxon-Test), where appropriate. Categorical variables were compared using the chi-square test. All statistical analyses were conducted using IBM SPSS Statistics for Windows Version 23.0 (IBM Corp, Armonk, NY, USA).

\section{Results}

Baseline characteristics

A total of 68 women with pathogenic BRCA1 or BRCA2 mutations were included in the study. 46 out of 68 (68\%) participating females had been diagnosed with cancer before inclusion, 43 suffering from breast cancer, two had ovarian cancer and one with both ovarian and breast cancer.

Participants' baseline data regarding health and $B R C A$ mutation status as well as age in both the CG and IG are shown in Table 1 . The groups did not differ regarding age, $\mathrm{BMI}$ or $\mathrm{VO}_{2}$ peak. BRCA carriers were nonobese and of similar weight as the German average female population in this age group [29]. Median $\mathrm{VO}_{2} \max$ at baseline describing the cardio-pulmonary fitness status was $25.9 \mathrm{ml} / \mathrm{kg} / \mathrm{min}$ in our cohort. This value was between Canadian breast cancer survivors $\left(\mathrm{VO}_{2}\right.$ peak of $21.4 \pm 5$ and $\mathrm{O}_{2}$ at VT1 of $\left.14.9 \pm 2.9 \mathrm{ml} / \mathrm{kg} / \mathrm{min}\right)$ and healthy controls $(29.1 \pm 6$ and $18.1 \pm 3.5 \mathrm{ml} / \mathrm{kg} / \mathrm{min}$ respectively) [30].

\section{Feasibility outcomes Completion of the study}

Fifty-five out of 68 women completed the study after 1 year (81\%) (Fig. 1). Of 33 participants allocated to the IG, 26 (79\%) women completed 12 months. Five of seven participants discontinuing the intervention dropped out during the first 3 months $(n=4$ because of low motivation, $n=3$ disease-related). Drop-outs in the IG were slightly older and had a lower BMI compared to the non-drop-outs. There were no relevant differences regarding health status between the groups (Table 2).

Six women in the CG discontinued the study, mainly for reasons related to lack of motivation $(n=5)$. Twenty-nine women (82\%) of the CG completed the study program. Details of the drop-outs are shown in Table 2. In comparing baseline characteristics of dropouts and non-drop-outs, no relevant differences in health or fitness status, activity levels, age or BMI were found. The results are shown in Table 2 .

Table 1 Baseline characteristics of study participants

\begin{tabular}{|c|c|c|c|c|}
\hline & $\begin{array}{l}\text { Intervention group } \\
n=33\end{array}$ & $\begin{array}{l}\text { Control group } \\
n=35\end{array}$ & $\begin{array}{l}\text { Total } \\
n=68\end{array}$ & $P$-value \\
\hline $\begin{array}{l}\text { Cancer, n } \\
\text { - Breast, n } \\
\text { - Ovarian, n } \\
\text { - both, n }\end{array}$ & $\begin{array}{l}23 \\
21 \\
1 \\
1\end{array}$ & $\begin{array}{l}23 \\
22 \\
1 \\
0\end{array}$ & $\begin{array}{l}46 \\
43 \\
2 \\
1\end{array}$ & 0.728 \\
\hline$B R C A-1 /-2, \mathrm{n}$ & $24 / 9$ & $18 / 17$ & $42 / 26$ & 0.073 \\
\hline $\mathrm{Age}^{\mathrm{a}}, \mathrm{yrs}$ & $41(27-72)$ & $41(24-68)$ & $41(24-72)$ & 0.839 \\
\hline $\mathrm{BMI}^{\mathrm{a}}, \mathrm{kg} / \mathrm{m}^{2}$ & $22.2(18.0-45.4)$ & $23.6(18.3-42.2)$ & $23.2(18.0-45.4)$ & 0.482 \\
\hline $\mathrm{VO}_{2}$ peak $^{\mathrm{a}}, \mathrm{ml} / \mathrm{kg} / \mathrm{min}$ & $24(12-42)$ & $28(15-38)$ & $26(12-42)$ & 0.597 \\
\hline Drop-out, $\mathrm{n}$ & 7 & 6 & 13 & 0.672 \\
\hline
\end{tabular}

${ }^{\mathrm{a}}$ Median (Range) 


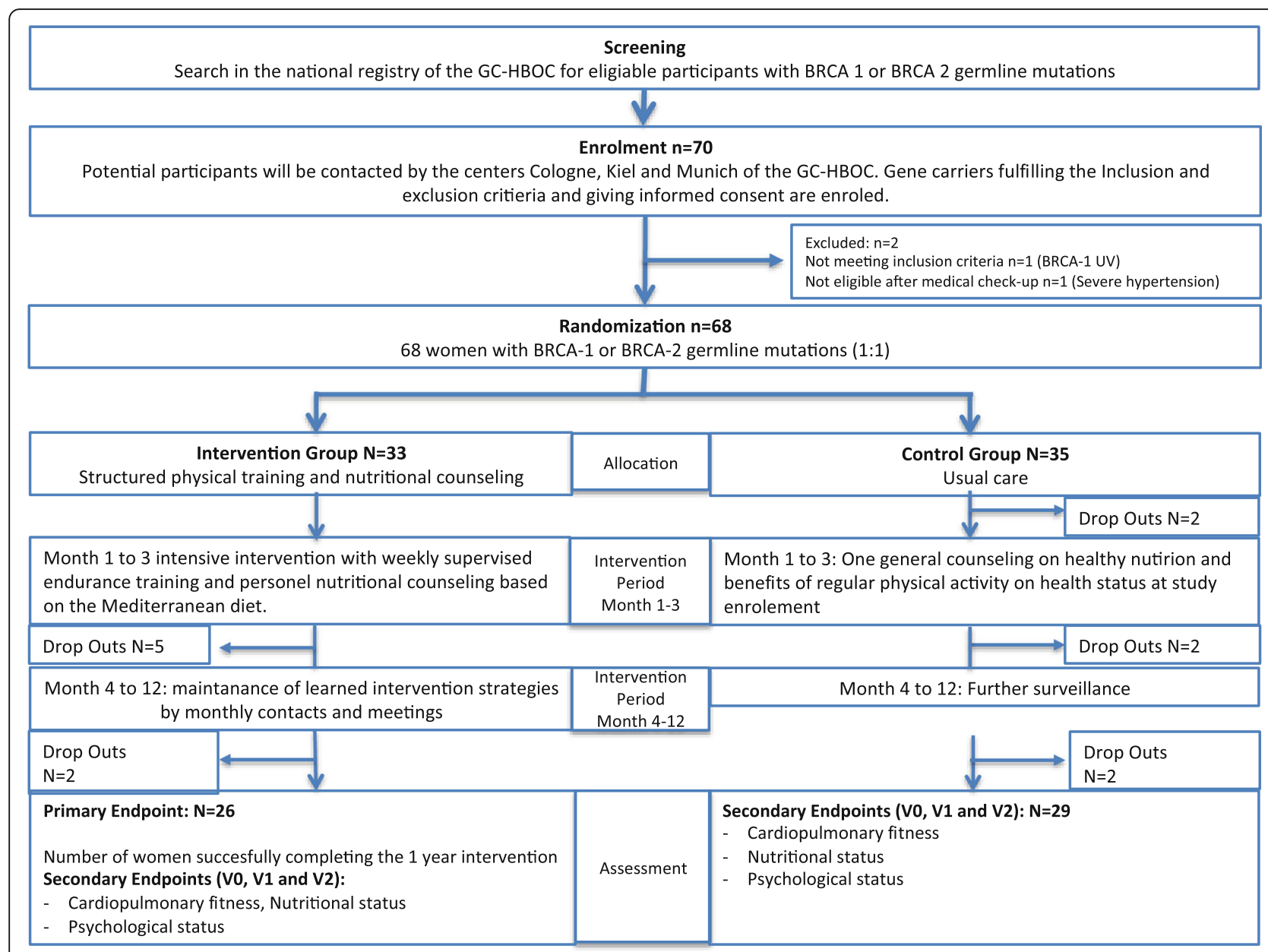

Fig. 1 CONSORT flow diagram for LIBRE-1 pilot study [45]

Table 2 Baseline characteristic of drop-outs

\begin{tabular}{|c|c|c|c|c|}
\hline Drop-outs & $\begin{array}{l}\text { Intervention group } \\
n=7\end{array}$ & $\begin{array}{l}\text { Control group } \\
n=6\end{array}$ & $\begin{array}{l}\text { Total } \\
n=13\end{array}$ & $P$-value \\
\hline Drop-out period, $\mathrm{n}$ & & & & 0.945 \\
\hline $\begin{array}{l}\text { - Months 1-3 } \\
\text { - Months 4-12 }\end{array}$ & $\begin{array}{l}5 \\
2\end{array}$ & $\begin{array}{l}4 \\
2\end{array}$ & $\begin{array}{l}9 \\
4\end{array}$ & \\
\hline Reason, n & & & & 0.445 \\
\hline $\begin{array}{l}\text { - Motivation-related } \\
\text { - Disease-related }\end{array}$ & $\begin{array}{l}4 \\
3\end{array}$ & $\begin{array}{l}5 \\
1\end{array}$ & $\begin{array}{l}9 \\
4\end{array}$ & \\
\hline Cancer, n & 5 & 4 & 9 & 0.945 \\
\hline Age $^{a}$, years & $45(30-51)$ & $34(26-46)$ & $39(26-51)$ & 0.138 \\
\hline $\mathrm{BMI}^{\mathrm{a}}, \mathrm{kg} / \mathrm{m}^{2}$ & $20.9(19.8-26.9)$ & $23.7(20.7-38.6)$ & $23.1(19.8-38.6)$ & 0.138 \\
\hline $\mathrm{VO}_{2}$ peak $^{\mathrm{a}}, \mathrm{ml} / \mathrm{kg} / \mathrm{min}$ & $30(20-32)$ & $24.5(16-34)$ & $26(16-34)$ & 0.543 \\
\hline $\mathrm{O}_{2}$ at $\mathrm{VT} 1^{\mathrm{a}}, \mathrm{ml} / \mathrm{kg} / \mathrm{min}$ & $14(9-19)$ & $13.5(10-25)$ & $14(9-25)$ & 0.731 \\
\hline$I P A Q, M^{2} T^{a} \min / w k$ & $3366(1552-12,561)$ & $9750(4278-14,085)$ & $3990(1552-14,085)$ & 0.042 \\
\hline
\end{tabular}

${ }^{\mathrm{a}}$ Median (Range) 


\section{Adherence to intervention}

The adherence to the intervention by participants who completed the 12 months of the study was relatively high and is illustrated in Table 3. Twenty-one of 26 women attended five or six of the six planned nutritional courses. The adherence to the training sessions was similar: 21 of the 26 women performed at least 26 of the 36 planned training sessions within the first 3 months. Combining both interventions, 19 out of 26 participants attended at least $70 \%$ of both the nutritional and physical training classes. The combined overall adherence rate was $73 \%$. Participants with positive or negative adherence showed no significant differences regarding health or fitness status, activity level, age or BMI.

\section{Recruitment and retention}

The first participant was recruited on the 24th of February 2014 and the last one on the 31st of July 2014. On the 15th of October 2015 the last participant finished the intervention program and completed V2. The 68 participants were recruited in less than 6 months. The recruitment rate per center was different: eight in Cologne, 23 in Kiel and 37 in Munich. Data entry was completed on April 30th, 2016. The retention period of the study (first patient in until data entry completion) was 26 months.

\section{Adverse events and safety}

Neither adverse events related to this study nor safety issues such as injuries during training were reported.

\section{Satisfaction with the study}

Eighteen out of 26 (69\%) women of the IG who completed the study answered our questions on satisfaction with the study. $83 \%(15 / 18)$ attested grade 1 (good) or 2 (reasonable) regarding overall satisfaction with the study and care. 56\% (10/18) judged the extent and feasibility of the physical training as good or reasonable. $78 \%(14 / 18)$ evaluated the nutritional intervention as good and feasible. $83 \%(15 / 18)$ would participate in such a study again.

Twenty two out of 29 (76\%) participants of the CG, who completed the study answered the questionnaire. $64 \%(14 / 22)$ attested a good grade regarding overall satisfaction with the study and care. $41 \%(9 / 22)$ were satisfied with the general introductory lecture on positive effects of physical activity and healthy eating. 41\% (9/22) evaluated the recommendations as good and feasible. $77 \%(17 / 22)$ would participate again in such a study. The results are presented in detail in Table 4.

Table 3 Adherence to the lifestyle intervention program within the first 3 months and baseline characteristics $(n=26)$

\begin{tabular}{|c|c|c|c|}
\hline & $\begin{array}{l}\text { Adherence positive } \\
\text { ( } \geq 70 \% \text { participation in the intervention sessions) }\end{array}$ & $\begin{array}{l}\text { Adherence negative } \\
\text { (<70\% participation in the intervention sessions) }\end{array}$ & $P$-value \\
\hline Nutrition courses & $21 / 26(81 \%)$ & $5 / 26(19 \%)$ & \\
\hline Cancer, n & 16 & 2 & 0.610 \\
\hline Age $^{*}$, years & $43(29-72)$ & $41(28-49)$ & 0.686 \\
\hline $\mathrm{BMI}^{*}, \mathrm{~kg} / \mathrm{m}^{2}$ & $23(18-45)$ & $24(20-37)$ & 0.610 \\
\hline $\mathrm{VO}_{2}$ peak $^{*}, \mathrm{ml} / \mathrm{kg} / \mathrm{min}$ & $24(12-42)$ & $23(16-41)$ & 0.952 \\
\hline $\mathrm{O}_{2}$ at $\mathrm{VT} 1^{*}, \mathrm{ml} / \mathrm{kg} / \mathrm{min}$ & $14(8-28)$ & $14(10-21)$ & 0.343 \\
\hline IPAQ, MET*min/wk & $5130(347-14,166)$ & $6167(4583-7812)$ & 0.629 \\
\hline Training courses & $21 / 26(81 \%)$ & $5 / 26(19 \%)$ & \\
\hline Cancer, n & 14 & 4 & 0.114 \\
\hline Age $^{*}$, years & $42(28-72)$ & $41(36-51)$ & 0.286 \\
\hline $\mathrm{BMI}^{*}, \mathrm{~kg} / \mathrm{m}^{2}$ & $23(18-45)$ & $24(20-37)$ & 0.857 \\
\hline $\mathrm{VO}_{2}$ peak ${ }^{*}, \mathrm{ml} / \mathrm{kg} / \mathrm{min}$ & $24(12-42)$ & $22(16-37)$ & 0.467 \\
\hline $\mathrm{O}_{2}$ at $\mathrm{VT} 1^{*}, \mathrm{ml} / \mathrm{kg} / \mathrm{min}$ & $14(8-28)$ & $15(10-21)$ & 1.000 \\
\hline IPAQ, MET*min/wk & $5376(347-14,166)$ & $5375(2826-7812)$ & 0.970 \\
\hline Nutrition and training & 19/26 (73\%) & $7 / 26(27 \%)$ & \\
\hline Cancer, n & 14 & 4 & 0.534 \\
\hline Age $^{*}$, years & $43(29-27)$ & $41(28-51)$ & 0.821 \\
\hline $\mathrm{BMI}^{*}, \mathrm{~kg} / \mathrm{m}^{2}$ & $23(18-45)$ & $24(20-37)$ & 0.778 \\
\hline $\mathrm{VO}_{2}$ peak $^{*}, \mathrm{ml} / \mathrm{kg} / \mathrm{min}$ & $24(12-42)$ & $23(16-41)$ & 0.955 \\
\hline $\mathrm{O}_{2}$ at $\mathrm{VT} 1^{*}, \mathrm{ml} / \mathrm{kg} / \mathrm{min}$ & $14(8-28)$ & $15(10-21)$ & 0.642 \\
\hline IPAQ, MET*min/wk & $5376(347-14,166)$ & $5576(2826-7812)$ & 0.974 \\
\hline
\end{tabular}


Table 4 Participants satisfaction with the study

\begin{tabular}{|c|c|c|c|c|c|c|c|}
\hline \multirow{2}{*}{$\begin{array}{l}\text { Rate of return } \\
\text { Items }\end{array}$} & \multicolumn{3}{|c|}{$\begin{array}{l}\text { Intervention group } \\
69 \%(18 / 26)\end{array}$} & \multicolumn{3}{|c|}{$\begin{array}{l}\text { Control group } \\
76 \%(22 / 29)\end{array}$} & \multirow[t]{2}{*}{$P$-value } \\
\hline & $\begin{array}{l}\text { "Good" } \\
\text { Grading 1-2 }\end{array}$ & $\begin{array}{l}\text { "Inter-mediate" } \\
\text { Grading 3-4 }\end{array}$ & $\begin{array}{l}\text { "Bad" } \\
\text { Grading 5-6 }\end{array}$ & $\begin{array}{l}\text { "Good" } \\
\text { Grading 1-2 }\end{array}$ & $\begin{array}{l}\text { "Inter-mediate" } \\
\text { Grading 3-4 }\end{array}$ & $\begin{array}{l}\text { "Bad" } \\
\text { Grading 5-6 }\end{array}$ & \\
\hline Overall satisfaction with the study and care & $15(83 \%)$ & $3(17 \%)$ & $0(0 \%)$ & $14(64 \%)$ & $7(32 \%)$ & $1(4.5 \%)$ & 0.096 \\
\hline Extent and feasibility of physical intervention (IG) & $10(56 \%)$ & $5(28 \%)$ & $3(17 \%)$ & not asked & & & \\
\hline Extent and feasibility of nutritional intervention (IG) & $14(78 \%)$ & $4(22 \%)$ & $0(0 \%)$ & not asked & & & \\
\hline \multirow{2}{*}{$\begin{array}{l}\text { Extent and feasibility of general information on } \\
\text { training and healthy eating (CG) }\end{array}$} & not asked & & & $9(41 \%)$ & $10(45 \%)$ & $2(9 \%)$ & \\
\hline & yes & No & & yes & & no & $p$-value \\
\hline Willingness to partake in such studies again & $15(83 \%)$ & $3(17 \%)$ & & 17 (77\%) & & $5(23 \%)$ & 0.683 \\
\hline
\end{tabular}

\section{Secondary outcome measurements}

The secondary outcome measures are summarized in Table 5. The BMI was chosen as a secondary outcome measure representing physical exercise and nutrition. The baseline BMI values, as well as the measurements after 3 and 12 months (V1 and V2) showed no significant differences in the IG compared to the CG. However, by comparing the difference $(\Delta)$ of BMI from baseline to V1, there was a decrease in the IG compared to the CG $(p=0.002)$. This effect was not significant after 12 months $(p=0.115)$.

Regarding nutrition the total daily calorie intake (TEI) measured by a questionnaire (EPIQ-FFQ) showed no differences in the intervention and control group at baseline, after 3 (V1) and 12 (V2) months. The amount of calorie intake was in median 1965-2234 kcal per day. Women of the control group reduced their total calorie intake (approximately $250 \mathrm{kcal} /$ day) after 12 months compared to the intervention group $(p=0.007)$. The amount of dietary fat accounts to about $39-40 \%$ of TEI with no difference between groups at any time point. A detailed subgroup analysis of macronutrient intake and micronutrient profiles will be published separately.

The median MEDAS being $7(2-10)$ at baseline in the IG is two score points higher compared to a median of 5 $(3-11)$ in the CG $(p=0.020)$. At V1 the difference is more considerable: $9(6-13)$ versus $6(3-12 ; p=0.001)$, but again reveals a consistent group difference of two score points at V2 being $8(5-13)$ in the IG and $6(2-13)$ in the CG $(p=0.001)$. When the MEDAS delta between $\mathrm{V} 2$ and baseline is compared between groups, the increase in the IG appears to be relevant ( $p=0.044)$.

Data on physical activity and physical fitness during intervention varied substantially among individuals and were not conclusive. $\mathrm{VO}_{2}$ peak improved in the IG after 3 months, but these effects diminished after 12 months, a finding often seen in intervention trials, as contact decreases. Also aerobic capacity $\left(\mathrm{O}_{2}\right.$ at VT1), an additional parameter of basic fitness did not improve (Table 5). These objectively measured data were not in line with subjective assessment of physical activity by the IPAQ questionnaire. While activity increased during intervention in the CG and even decreased in the IG, cardiopulmonary parameters changed vice versa (Table 5).

The screening scale data of chronic stress (SSCS) in the study population showed similar scores compared to a reference cohort of the German population (age 3159 years) [22]. The standard value for this age group is a score of 13 with a reference range of 6 to 24 score points [22]. The median SSCS scores of the IG and CG were always within the standard range, however revealed higher individual ranges from 0 to 41 scores compared to the reference range of 6 to 24 scores. This indicates that women with chronic stress experience have probably been included. After 12 months the participants of the IG significantly improved stress scores compared to the CG (IG: $14.6 \pm 3-41$; CG: $20.9 \pm 1-39 ; p=0.022$ ).

The health related quality of life was measured by EORTC QLQ-C30. Scale 1 measuring global health status and quality of life showed no significant differences between IG and CG at any time points. The median scores (63.1-73.3) were within the reference range [31]. More detailed data of the additional 14 scales of the EORTC QLQ-C30 as well as the eight scales of breast cancer specific module EORTC QLQ-BR23 will be published separately.

\section{Discussion}

LIBRE-1 is worldwide the first prospective randomized multicenter lifestyle intervention trial in $B R C A 1 / 2$ mutation carriers. This pilot study demonstrated the feasibility of recruiting and retaining women in a demanding and time-consuming structured intervention program including regular exercise (three exercise classes per week for 3 months) and nutrition education stressing the Mediterranean diet (six courses within 3 months). Additionally, we observed a favorable effect on BMI, chronic stress levels and changes in nutritional habits towards a Mediterranean eating pattern. 
Table 5 Secondary endpoints

\begin{tabular}{ll}
\hline & $\begin{array}{l}\text { Intervention group } \\
\text { Median (range) }\end{array}$ \\
\hline Body Mass Index, kg/m² & \\
Baseline (V0) & $22.2(18.0-45.2)(n=33)$ \\
3 Months (V1) & $23.4(17.3-44.8)(n=26)$ \\
12 Months (V2) & $24.1(18.6-46.3) n=22)$ \\
$\Delta$ V1-V0 & $-0.19(-4.7-0.8)(n=26)$ \\
$\Delta$ V2-V0 & $-0.16(-7.6-2.8)(n=22)$ \\
EPIQ-FFQ: energy intake, kcal/day & \\
Baseline (V0) & $1955.2(863.8-3530.5)(n=32)$ \\
3 Months (V1) & $2240.2(800.7-3673.0)(n=25)$ \\
12 Months (V2) & $2024.6(989.0-3516.9)(n=25)$ \\
$\Delta$ V1-V0 & $78.8(-1048.1-834.1)(n=24)$ \\
$\Delta$ V2-V0 & $133.3(-962.3-634.0)(n=24)$
\end{tabular}

EPIQ-FFQ: Fat calorie intake [\%energy intake]

$\begin{array}{ll}\text { Baseline (V0) } & 40.1(28.7-67.9)(n \\ 3 \text { Months (V1) } & 39.4(31.3-63.1)(n \\ \text { 12 Months (V2) } & 40.2(33.5-66.9)(n \\ \Delta \text { V1 - V0 } & 0.35(-14.32-8.38)(n \\ \Delta \text { V2 - V0 } & -1.30(-6.69-26.6) \\ \text { MEDAS: (0-14 score points) } & \\ \text { Baseline (V0) } & 7(2-10)(n=33) \\ \text { 3 Months (V1) } & 9(6-13)(n=26) \\ \text { 12 Months (V2) } & 8(5-13)(n=25) \\ \Delta \text { V1-V0 } & 2(-1-8)(n=26) \\ \Delta \text { V2-V0 } & 2(-2-6)(n=25)\end{array}$

$\begin{array}{ll}40.4(31.4-50.0)(n=32) & 0.968 \\ 40.3(30.9-60.0)(n=29) & 0.910 \\ 39.2(27.1-50.6)(n=27) & 0.504 \\ 0.49(-11.01-15.15)(n=28) & 0.971 \\ -2.22(-13.16-14.25)(n=26) & 0.367\end{array}$

$23.6(18.3-42.7)(n=35) \quad 0.482$

$24.4(18.3-44.8)(n=31) \quad 0.804$

$23.3(18.6-46.3)(n=27) \quad 0.833$

$0.32(-1.1-2.2)(n=31) \quad 0.002$

$0.034(-1.9-3.6)(n=27) \quad 0.115$

$2245.4(1060.4-3088.3)(n=32)$

0.045

$2085.8(780.7-2965.8)(n=29)$

0.761

$1936.0(308.1-3609.9)(n=27) \quad 0.405$

$-149.4(-741.4-653.7)(n=28)$

0.119

$-112.6(-1383.2-547.8)(n=26)$

0.007

IPAQ, MET*min/wk

Baseline (V0)

$4583(347-14,166)(n=31)$

$5(3-11)(n=31)$

0.020

$6(3-12)(n=29)$

0.001

$6(2-13)(n=27)$

0.001

$1(-3-4)(n=28)$

0.110

$0(-3-6)(n=25)$

0.044

3 Months (V1)

$4447(834-11,904)(n=26)$

$4215(300-15,624)(n=29)$

0.294

12 Months (V2)

$3754(1012-11,706)(n=24)$

$\Delta \mathrm{V} 1-\mathrm{V} 0$

$252(-7961-4878)(n=25)$

$\Delta \mathrm{V}_{2}-\mathrm{V}_{0}$

$-1878(-10,236-6084)(n=22)$

$3230(173-37,788)(n=30)$

0.212

$4528(189-56,943)(n=28) \quad 0.463$

$-125(-14,085-22,164)[27] \quad 0.654$

$961(-4178-41,310)(n=24) \quad 0.004$

$\mathrm{VO}_{2}$ peak, $\mathrm{ml} / \mathrm{kg} / \mathrm{min}$

Baseline (SE-VO)

$24(12-42)(n=33)$

$28(15-38)(n=35)$

0.597

3 Months (V1)

$26(15-42)(n=25)$

$27(14-40)(n=30)$

0.993

12 Months (V2)

$24(10-35)(n=22)$

$26(14-44)(n=23)$

0.459

$\Delta \mathrm{V} 1-\mathrm{V} 0$

$2(-6-10)(n=25)$

$0(-7-6)(n=30)$

0.146

$\Delta \mathrm{V}_{2}-\mathrm{V}_{0}$

$-1(-13-11)(n=22)$

$-3(-9-6)(n=23)$

0.045

$\mathrm{O}_{2}$ at $\mathrm{VT} 1, \mathrm{ml} / \mathrm{kg} / \mathrm{min}$

Baseline (SE/NO)

$14(8-28)(n=32)$

$16(10-28)(n=35)$

0.281

3 Months (V1)

$15(9-28)(n=23)$

$15(10-39)(n=30)$

0.787

12 Months (V2)

$14(6-26)(n=22)$

$\Delta \mathrm{V} 1-\mathrm{V} 0$

$1(-11-5)(n=22)$

$16(8-28)(n=23)$

0.068

$\Delta \mathrm{V}_{2}-\mathrm{V}_{0}$

$0(-12-8)(n=21)$

$-1.5(-9-18)(n=30)$

0.019

$0(-10-7)(n=23)$

1.000 
Table 5 Secondary endpoints (Continued)

\begin{tabular}{llll}
\hline & $\begin{array}{l}\text { Intervention group } \\
\text { Median (range) }\end{array}$ & $\begin{array}{l}\text { Control group } \\
\text { Median (range) }\end{array}$ \\
\hline $\begin{array}{ll}\text { QLQ-C30 scale 1 (0-100 scores) } \\
\text { Baseline (SEN0) }\end{array}$ & $68.7(17-100)(n=33)$ & $69.1(33-100)(n=35)$ & 0.938 \\
3 Months (V1) & $69.9(0-100)(n=26)$ & $73.3(17-100)(n=30)$ & 0.569 \\
12 Months (V2) & $70.1(25-100)(n=24)$ & $63.1(8-100)(n=26)$ & 0.309 \\
$\Delta$ V1-V0 & $1.3(n=26)$ & $3.3(n=30)$ & 0.603 \\
$\Delta$ V2-V0 & $2.1(n=24)$ & $-4.8(n=26)$ & 0.267 \\
SSCS (0-48 scores) & $15.3(3-38)(n=33)$ & $19.5(0-38)(n=35)$ & 0.062 \\
Baseline (SEN0) & $16.0(3-37)(n=26)$ & $18.2(0-39)(n=29)$ & 0.339 \\
3 Months (V1) & $14.6(3-41)(n=22)$ & $20.9(1-39)(n=27)$ & 0.022 \\
12 Months (V2) & $0.4(n=26)$ & $-0.9(n=29)$ & 0.388 \\
$\Delta$ V1-V0 & $-0.6(n=22)$ & $1.44(n=27)$ & 0.218 \\
$\Delta$ V2-V0 & & & \\
\hline
\end{tabular}

*Median (Range)

Bold $=$ significant $P$-values

First and foremost, the intervention appeared safe and was not associated with any adverse events. Furthermore, recruitment of the planned number of participants $(n=60)$ was relatively fast, in less than 6 months 68 women with $B R C A$ germline mutations were enrolled. The BRCA carriers were not obese and their BMI comparable to the healthy general population [29]. Median baseline fitness levels seemed to be below average, however, the group investigated was small and $68 \%$ were diseased. The median $\mathrm{VO}_{2}$ peak was comparable to German breast cancer patients after chemotherapy [32, 33].

Motivation and adherence to the intervention was high. This might be explained by awareness of increased lifetime risks of cancer $(55-60 \%$ for breast and $16-59 \%$ for ovarian cancer) [2] as well as the fact of being diagnosed with cancer before. This resulted in an overall completion rate of $81 \%$ after 12 months. $21 \%$ of the women allocated to the intervention and $18 \%$ randomized to the control group discontinued the study. In the control group the main reason for abandoning the study was the disappointment of not being randomized to the intervention group. In the intervention group the reasons were mainly lack of motivation, but also disease-related like progression of cancer or new diagnosis of cancer. However, the high overall acceptance rate and relatively low rate of attrition suggest that the intervention was well received. Moreover, age, BMI, health or fitness status had no influence on drop-out rates.

In comparable randomized pilot lifestyle intervention trials in breast cancer patients, similar but also higher drop-out rates have been reported ranging from 19 to $41 \%$ in exercise intervention studies [34] and in nutritional intervention between 17 and 23\% [13, 35]. In a randomized feasibility study similar to ours combining nutritional and training intervention for 3 months performed within the Scottish breast cancer-screening program, the same total drop-out rate of $19 \%$ as in our study was found [36]. Interestingly, in the Scottish study cohort $44 \%$ of the 80 participants reported a positive family history of breast cancer. This underlines the hypothesis that breast cancer awareness itself resulting e.g. from a positive family history will improve attitude towards adapting lifestyle habits.

Adherence to the intervention program (>70\% of the intervention classes (18)) was an additional important parameter for assessing feasibility of the LIBRE trial. Combining results of nutrition and exercise training courses, $73 \%$ of the women in the intervention group fulfilled the $70 \%$ threshold. $81 \%$ of the participants in the intervention group achieved the exercise training requirements. Compared to other lifestyle intervention trials these adherence rates were high [37]. In previous trials adherence to dietary regimens was higher than for exercise intervention [38]. Therefore, we conclude that our intervention program is feasible and practicable.

Moreover, the participants attested a high satisfaction with the study and care within the trial, especially those allocated to the intervention arm. Only $17 \%$ stated that the physical training was not feasible or too extensive. Regarding nutritional intervention no concerns were reported. The rating of the control group was slightly worse compared to the intervention group regarding overall satisfaction with the study and care, re-participation, extent and feasibility of the lifestyle intervention. This may be explained by the women's disappointment of having been randomized to the control group. This is supported by the fact that predictors 
for adherence or non-adherence could not be identified. Age, BMI, health or fitness status, which may have influenced adherence, were not different between the groups. However, numbers of women enrolled are still rather small and we will further investigate this issue in the subsequent larger LIBRE-2 trial.

We observed some significant effects on secondary outcomes in the intervention group compared to the controls (Table 5). However, since multiple comparisons were performed between study arms, these significant findings have to be interpreted with great caution. Due to the exploratory nature of this pilot study, we deliberately did not correct for multiple testing. Thus, significant findings can only be interpreted as hypothesis generating rather than confirmatory results. Moreover, because of the low sample size of this pilot study the statistical power to detect truly existing differences between the study arms with regard to secondary outcome measures was low.

The participants' calorie intake corresponded to the reference values of energy requirements for medium physical activity, according to recommendations of the German (D), Austrian (A) and Swiss (CH) Nutrition Societies (D-A-CH reference values). These adopt recommendations of the EFSA - Scientific Opinion on Dietary Reference Values for energy [39]. However, the calorie intake of our study population was somewhat above the median intake of $1833 \mathrm{kcal} /$ day, as described in the German National Nutrition Survey II (NVS II), the study forming the basis of the analysis of Heuer et al. [40]. Interestingly, caloric intake in the intervention group did in fact slightly increase over 3 or 12 months, but was slightly reduced in the control group after 12 months. A caloric restriction was not a primary aim of the Mediterranean diet intervention, except for women with a BMI $>35 \mathrm{~kg} / \mathrm{m}^{2}$, but was obviously anticipated in the control group receiving only one nutrition course. The median proportion of dietary fat of TEI was $40 \%$ in both groups and therefore above the recommendation value of $30 \%$ [39]. Participants of the NVS II had a median fat intake of $35 \%$.

According to Léon-Munoz et al. [41] a MEDAS score $\geq 9$ shows strong adherence, and a MEDAS score $\geq$ 7 modest adherence to the Mediterranean Diet (MD). As expected, there was almost no conformance in our study population in both groups to a MD pattern before the intervention [41]. The median baseline score of our study cohort of 7 (range 2-10) in the IG and 5 [3-11] in the control $(p=0.020)$ is comparable to the results of the Spanish cohort of the general population (mean \pm SE: $6.34 \pm 0.03$ ) [41], but lower than the baseline values reported in the PREDIMED study [14] (mean \pm SE: Mediterranean Diet with extra virgin olive oil: $8.95 \pm 1.79$; MD with Nuts: $8.92 \pm 1.92$; Control diet: $8.42 \pm 1.81$ ). So far, there is no data on MEDAS scores in the general German population.

As MEDAS was not a stratification parameter, unfortunately a random group difference was observed at baseline, which persisted during study timeline. However, during the 12-month nutrition education, the intervention group increased their MEDAS value compared to baseline. According to Léon-Munoz et al., these participants with a median MEDAS score of eight obviously present a better adherence to the MD after intervention than the control with six score points [41], despite this consistent group difference.

The participants of the control group, which at baseline received a single group lesson on general information about healthy nutrition according to recommendations of the German Nutrition Society (DGE), expectably did not achieve much higher MEDAS results; however, a slight increase in MEDAS appears at V1 and remains at V2. The participants might have been motivated to fulfill recommendations of the DGE, and there is a considerable overlap between DGE recommendations on healthy nutrition and the typical MD pattern. Therefore, the contents of the group sessions on MD seem to be successfully implemented especially by the intervention group.

Data on physical activity and improvement of physical fitness during intervention are equivocal. On the one side physical activity assessed per questionnaire decreased during active intervention over the first 3 months and unexpectedly increased in the usual care group (Table 5). In contrast, aerobic cardiopulmonary fitness improved in the intervention group, a finding directly related to increased regular physical activity. Physiologically this cannot readily be explained and it seems likely that either the questionnaire assessments were inaccurate, or the participants in the intervention group exercised deliberately for supervised training sessions in the center, thereby improving physical fitness, but did not increase, but rather decreased daily physical activity.

The health related quality of life measured in our trial by EORTC-QLQ-C30 was in the reference range and showed neither differences between the arms nor during intervention. The baseline stress levels in the study population were within the reference range of the German population (age 31-59 years). However, after 12 months stress was significantly reduced probably due to the active lifestyle intervention, illustrated by significantly lower stress scores compared to the control group. These results confirm previous results that lifestyle intervention has a positive influence on mental health [15-17, 42, 43].

\section{Conclusions}

In conclusion, the results of this pilot study were positive regarding feasibility outcome measures such as 
completion of the study, adherence, safety and satisfaction with the study. Additionally, the intervention indicated that relevant beneficial effects on body weight, stress levels and changes in nutritional behavior towards a Mediterranean-eating pattern can be achieved. Data are, however, limited to a small group of patients. These results will form the basis for a larger randomized trial (LIBRE-2) with an estimated sample size of 600 BRCA1 and $B R C A 2$ mutation carriers aiming at improvement of BMI, aerobic and maximal exercise capacity and adherence to a Mediterranean diet [44]. This large intervention study will generate first data on whether breast cancer incidence and prognosis can be influenced by lifestyle intervention. Results of such a large multicenter intervention trial would have a significant impact on clinical recommendations and guidelines for breast cancer prevention.

\section{Abbreviations}

BMI: Body mass index; CG: Control group; DGE: German Nutrition Society (Deutsche Gesellschaft Ernährung); EFSA: European Food Safety Authority; GC-HBOC: German Consortium for Hereditary Breast and Ovarian Cancer; IG: Intervention group; LIBRE-1: Lifestyle Intervention study in women with hereditary breast and ovarian cancer, 1 = pilot; MD: Mediterranean diet; NVS II: German National Nutrition Survey II; TEl: Total daily calorie intake

\section{Acknowledgments}

The authors thank the self-help group BRCA Network (https://www.brcanetzwerk.de), Mirjam Ullrich, Ute Reuning, Ute Enders and Daniela Schemmer for support.

\section{Funding}

The study is funded by the German Cancer Aid (Deutsche Krebshilfe: http://www.krebshilfe.de) within the Priority Program "Primary Prevention of Cancer" (Grant no. 110013). The title of the grant is "Influence of physical activity and nutrition on quality of life, stress coping, BMI and fitness in patients with hereditary breast and ovarian cancer (HBOC): A multicenter, interdisciplinary, prospective, randomized basic study to analyze the feasibility of lifestyle intervention in women with BRCA mutations with the subsequent aim to further analyze the influence of lifestyle intervention on the incidence, prognosis and mortality of HBOC."

\section{Availability of data and materials}

Data are available from the University of Leipzig (Christoph Engel) Institutional Data Access / Ethics Committee for researchers who meet the criteria for access to confidential data.

Informed consent did not foresee to make individual data of BRCA mutation carriers available to the public. However, anonymized data can be provided to interested scientists on request.

\section{Authors' contributions}

MK, CE, SB, MS and MH participated in the study design, study conduct/data collection and in writing the final manuscript; $A B, R D, M B, K P, S G, J$ and MYD participated in the study design and study conduct/data collection and the critical revision of the manuscript. RS, KR, UN, VS, NM and ML participated in the study conduct and data collection. All authors have approved the final version of the manuscript.

\section{Ethics approval and consent to participate}

Women shall participate in the study voluntarily and give written informed consent prior to study begin. They are informed that they can retract their participation at any time without disclosing any reasons and without negative consequences for their future medical care. The ethics review board of the Klinikum Rechts der Isar of the Technical University of Munich has approved the study protocol (Reference 5686/13) as well as the ethics committee of the faculty of Medicine of the University Cologne and Kiel (Reference 13-053 and
Reference B 235/13). The study is planned and conducted in accordance with medical professional codex and the Helsinki Declaration of 1996 as well as the German Federal Data Protection Act (BDSG). The trial has been registered at ClinicalTrials.gov (reference: NCT02087592).

\section{Consent for publication}

Not applicable.

\section{Competing interests}

The authors declare that they have no competing interests.

\section{Publisher's Note}

Springer Nature remains neutral with regard to jurisdictional claims in published maps and institutional affiliations.

\section{Author details}

${ }^{1}$ Department of Gynecology and Center for Hereditary Breast and Ovarian Cancer, Klinikum rechts der Isar, Technical University Munich (TUM), Ismaninger Str. 22, 81675 Munich, Germany. ${ }^{2}$ Institute for Medical Informatics, Statistics and Epidemiology, University of Leipzig, Haertelstrasse 16-18, 04107 Leipzig, Germany. ${ }^{3}$ Department of Prevention and Sports Medicine, Klinikum rechts der Isar, Technical University Munich (TUM), Georg-Brauchle Ring 56, 80638 Munich, Germany. ${ }^{4}$ Institute for Nutritional Medicine, University Hohenheim, Fruwirthstr. 12, 70593 Stuttgart, Germany. ${ }^{5}$ Institute for Medical Psychology and Sociology, University Hospital Schleswig-Holstein, Campus Kiel, Preusserstr. 1 - 9, 24105 Kiel, Germany. ${ }^{6}$ Center for Hereditary Breast and Ovarian Cancer, University Hospital Cologne, Kerpener Str. 34, 50931 Cologne, Germany. ${ }^{7}$ Department of Internal Medicine 1, University Hospital Schleswig-Holstein, Campus Kiel, Arnold-Heller-Strasse 3, 24105 Kiel, Germany. ${ }^{8}$ Else Kroener-Fresenius Prevention Center, Klinikum rechts der Isar, Technical University Munich (TUM), Ismaninger Str. 22, 81675 Munich, Germany.

Received: 25 January 2017 Accepted: 30 October 2017

Published online: 10 November 2017

\section{References}

1. Mavaddat N, Pharoah PD, Michailidou K, Tyrer J, Brook MN, Bolla MK, et al. Prediction of breast cancer risk based on profiling with common genetic variants. J Natl Cancer Inst. 2015;107(5):djv036. doi:10.1093/jnci/djv036.

2. Mavaddat N, Peock S, Frost D, Ellis S, Platte R, Fineberg E, et al. Cancer risks for BRCA1 and BRCA2 mutation carriers: results from prospective analysis of EMBRACE. J Natl Cancer Inst. 2013;105(11):812-22.

3. Easton DF, Pharoah PD, Antoniou AC, Tischkowitz M, Tavtigian SV, Nathanson KL, et al. Gene-panel sequencing and the prediction of breastcancer risk. N Engl J Med. 2015;372(23):2243-57.

4. Antoniou AC, Kuchenbaecker KB, Soucy P, Beesley J, Chen X, McGuffog L, et al. Common variants at 12p11, 12q24, 9p21,9q31.2 and in ZNF365 are associated with breast cancer risk for BRCA1 and/or BRCA2 mutation carriers. Breast cancer research : BCR. 2012;14(1):R33.

5. Bissonauth V, Shatenstein B, Fafard E, Maugard C, Robidoux A, Narod S, et al. Weight history, smoking, physical activity and breast cancer risk among French-Canadian women non-carriers of more frequent BRCA1/2 mutations. Journal of cancer epidemiology. 2009;2009:748367.

6. Pettapiece-Phillips R, Narod SA, Kotsopoulos J. The role of body size and physical activity on the risk of breast cancer in BRCA mutation carriers. Cancer Causes Control. 2015;26(3):333-44.

7. Friedenreich CM, Woolcott CG, McTiernan A, Ballard-Barbash R, Brant RF, Stanczyk FZ, et al. Alberta physical activity and breast cancer prevention trial: sex hormone changes in a year-long exercise intervention among postmenopausal women. J Clin Oncol. 2010;28(9):1458-66.

8. Holmes MD, Chen WY, Feskanich D, Kroenke CH, Colditz GA. Physical activity and survival after breast cancer diagnosis. JAMA. 2005;293(20):2479-86.

9. Backman M, Wengstrom Y, Johansson B, Skoldengen I, Borjesson S, Tarnbro $S$, et al. A randomized pilot study with daily walking during adjuvant chemotherapy for patients with breast and colorectal cancer. Acta oncologica (Stockholm, Sweden). 2014;53(4):510-20.

10. Eliassen AH, Hankinson SE, Rosner B, Holmes MD, Willett WC. Physical activity and risk of breast cancer among postmenopausal women. Arch Intern Med. 2010;170(19):1758-64. 
11. Rosato V, Bosetti C, Talamini R, Levi F, Montella M, Giacosa A, et al. Metabolic syndrome and the risk of breast cancer in postmenopausal women. Ann Oncol. 2011;22(12):2687-92.

12. Ewertz $M$, Jensen MB, Gunnarsdottir KA, Hojris I, Jakobsen EH, Nielsen $D$, et al. Effect of obesity on prognosis after early-stage breast cancer. J Clin Oncol. 2011;29(1):25-31.

13. Chlebowski RT, Blackburn GL, Thomson CA, Nixon DW, Shapiro A, Hoy MK, et al. Dietary fat reduction and breast cancer outcome: interim efficacy results from the Women's intervention nutrition study. J Natl Cancer Inst. 2006;98(24):1767-76.

14. Toledo E, Salas-Salvado J, Donat-Vargas C, Buil-Cosiales P, Estruch R, Ros E, et al. Mediterranean diet and invasive breast cancer risk among women at high cardiovascular risk in the PREDIMED trial: a randomized clinical trial. JAMA Intern Med. 2015;175(11):1752-60.

15. Culver JL, Arena PL, Antoni MH, Carver CS. Coping and distress among women under treatment for early stage breast cancer: comparing African Americans, Hispanics and non-Hispanic whites. Psycho-Oncology. 2002; 11(6):495-504.

16. Wimberly SR, Carver CS, Antoni MH. Effects of optimism, interpersonal relationships, and distress on psychosexual well-being among women with early stage breast cancer. Psychol Health. 2008:23(1):57-72.

17. Courneya KS, McKenzie DC, Gelmon K, Mackey JR, Reid RD, Yasui Y, et al. A multicenter randomized trial of the effects of exercise dose and type on psychosocial distress in breast cancer patients undergoing chemotherapy. Cancer Epidemiol Biomark Prev. 2014;23(5):857-64.

18. Kiechle M, Engel C, Berling A, Hebestreit K, Bischoff SC, Dukatz R, et al. Effects of lifestyle intervention in BRCA1/2 mutation carriers on nutrition, BMI, and physical fitness (LIBRE study): study protocol for a randomized controlled trial. Trials. 2016;17:368.

19. Kiechle M, Engel C, Berling A, Hebestreit K, Bischoff S, Dukatz R, et al. Lifestyle intervention in BRCA 1/2-mutation carriers: study protocol for a prospective, randomized, controlled clinical feasibility trial (LIBRE-1 study). Pilot and feasibility studies. 2016;2:74.

20. Sprangers MA, Groenvold M, Arraras Jl, Franklin J, te Velde A, Muller M, et al. The European Organization for Research and Treatment of cancer breast cancer-specific quality-of-life questionnaire module: first results from a three-country field study. J Clin Oncol. 1996;14(10):2756-68.

21. Aaronson NK, Ahmedzai S, Bergman B, Bullinger M, Cull A, Duez NJ. The European Organization for Research and Treatment of cancer QLQ-C30: a quality-of-life instrument for use in international clinical trials in oncology. J Natl Cancer Inst. 1993;85(5):365-76.

22. Schulz P, Schlotz W, Becker P. TICS. Trierer Inventar zum chronischen Stress. Göttingen, Germany: Hogrefe; 2004.

23. Boeing $H$, Bohlscheid-Thomas S, Voss S, Schneeweiss S, Wahrendorf J. The relative validity of vitamin intakes derived from a food frequency questionnaire compared to 24-hour recalls and biological measurements: results from the EPIC pilot study in Germany. European prospective investigation into cancer and nutrition. Int J Epidemiol. 1997;26(Suppl 1):S82-90.

24. Bohlscheid-Thomas S, Hoting I, Boeing H, Wahrendorf J. Reproducibility and relative validity of energy and macronutrient intake of a food frequency questionnaire developed for the German part of the EPIC project. European prospective investigation into cancer and nutrition. Int J Epidemiol. 1997; 26(Suppl 1):S71-81.

25. Kroke A, Klipstein-Grobusch K, Voss S, Moseneder J, Thielecke F, Noack R. Validation of a self-administered food-frequency questionnaire administered in the European prospective investigation into cancer and nutrition (EPIC) study: comparison of energy, protein, and macronutrient intakes estimated with the doubly labeled water, urinary nitrogen, and repeated 24-h dietary recall methods. Am J Clin Nutr. 1999;70(4):439-47.

26. Hebestreit K, Yahiaoui-Doktor M, Engel C, Vetter W, Siniatchkin M, Erickson $\mathrm{N}$, et al. Validation of the German version of the Mediterranean diet adherence screener (MEDAS) questionnaire. BMC Cancer. 2017;17(1):341.

27. Van Holle V, De Bourdeaudhuij I, Deforche B, Van Cauwenberg J, Van Dyck D. Assessment of physical activity in older Belgian adults: validity and reliability of an adapted interview version of the long international physical activity questionnaire (IPAQ-L). BMC Public Health. 2015;15:433.

28. Grimm EK, Swartz AM, Hart T, Miller NE, Strath SJ. Comparison of the IPAQshort form and accelerometry predictions of physical activity in older adults. J Aging Phys Act. 2012;20

29. Mensink GB, Schienkiewitz A, Haftenberger M, Lampert T, Ziese T, ScheidtNave C. Overweight and obesity in Germany: results of the German health interview and examination survey for adults (DEGS1). Bundesgesundheitsblatt Gesundheitsforschung Gesundheitsschutz. 2013; 56(5-6):786-94.

30. O'Donnell DE, Webb KA, Langer D, Elbehairy AF, Neder JA, Dudgeon DJ. Respiratory factors contributing to exercise intolerance in breast cancer survivors: a case-control study. J Pain Symptom Manag. 2016;52(1):54-63.

31. Scott NW, Fayers PM, Aaronson NK, Bottomley A, de Graeff A, Groenvold M, et al. Differential item functioning (DIF) in the EORTC QLQ-C30: a comparison of baseline, on-treatment and off-treatment data. Qual Life Res. 2009;18(3):381-8.

32. Scharhag-Rosenberger $F$, Kuehl R, Klassen O, Schommer $K$, Schmidt ME, Ulrich CM, et al. Exercise training intensity prescription in breast cancer survivors: validity of current practice and specific recommendations. Journal of cancer survivorship : research and practice. 2015:9(4):612-9.

33. Kuehl R, Scharhag-Rosenberger F, Schommer K, Schmidt ME, Dreger $P$, Huber $\mathrm{G}$, et al. Exercise intensity classification in cancer patients undergoing allogeneic HCT. Med Sci Sports Exerc. 2015;47(5):889-95.

34. Mutrie N, Campbell AM, Whyte F, McConnachie A, Emslie C, Lee L, et al. Benefits of supervised group exercise programme for women being treated for early stage breast cancer: pragmatic randomised controlled trial. BMJ (Clinical research ed). 2007:334(7592):517.

35. Henderson MM, Kushi LH, Thompson DJ, Gorbach SL, Clifford CK, Insull W Jr et al. Feasibility of a randomized trial of a low-fat diet for the prevention of breast cancer: dietary compliance in the Women's health trial vanguard study. Prev Med. 1990;19(2):115-33.

36. Anderson AS, Macleod M, Mutrie N, Sugden J, Dobson H, Treweek S, et al. Breast cancer risk reduction-is it feasible to initiate a randomised controlled trial of a lifestyle intervention programme (ActWell) within a national breast screening programme? The international journal of behavioral nutrition and physical activity. 2014;11:156

37. Linke SE, Gallo LC, Norman GJ. Attrition and adherence rates of sustained vs. intermittent exercise interventions. Annals of behavioral medicine : a publication of the Society of Behavioral Medicine. 2011; 42(2):197-209.

38. Demark-Wahnefried W, Case LD, Blackwell K, Marcom PK, Kraus W, Aziz N, et al. Results of a diet/exercise feasibility trial to prevent adverse body composition change in breast cancer patients on adjuvant chemotherapy. Clin Breast Cancer. 2008;8(1):70-9.

39. EFSA Panel on Dietetic Products NaAN. Scientific opinion on dietary reference values for energy. EFSA J. 2013;11(1)

40. Heuer T, Krems C, Moon K, Brombach C, Hoffmann I. Food consumption of adults in Germany: results of the German National Nutrition Survey II based on diet history interviews. Br J Nutr. 2015;113(10):1603-14.

41. Leon-Munoz LM, Guallar-Castillon P, Graciani A, Lopez-Garcia E, Mesas AE, Aquilera MT, et al. Adherence to the Mediterranean diet pattern has declined in Spanish adults. J Nutr. 2012;142(10):1843-50.

42. Antoni MH, Lechner S, Diaz A, Vargas S, Holley H, Phillips K, et al. Cognitive behavioral stress management effects on psychosocial and physiological adaptation in women undergoing treatment for breast cancer. Brain Behav Immun. 2009;23(5):580-91.

43. Antoni MH, Lehman JM, Kilbourn KM, Boyers AE, Culver JL, Alferi SM, et al. Cognitive-behavioral stress management intervention decreases the prevalence of depression and enhances benefit finding among women under treatment for early-stage breast cancer. Health psychology : official journal of the Division of Health Psychology, American Psychological Association. 2001:20(1):20-32.

44. Lancaster GA, Dodd S, Williamson PR. Design and analysis of pilot studies: recommendations for good practice. J Eval Clin Pract. 2004; 10(2):307-12

45. Eldridge SM, Chan CL, Campbell MJ, Bond CM, Hopewell S, Thabane L, et al. CONSORT 2010 statement: extension to randomised pilot and feasibility trials. Pilot and feasibility studies. 2016;2:64. 